\title{
Prevalence of conventional risk factors and lipid profiles in patients with acute coronary syndrome and significant coronary disease
}

This article was published in the following Dove Press journal:

Therapeutics and Clinical Risk Management

6 October 2014

Number of times this article has been viewed

\author{
Héctor González-Pacheco' \\ Jesús Vargas-Barrón ${ }^{2}$ \\ Maite Vallejo² \\ Yigal Piña-Reyna ${ }^{3}$ \\ Alfredo Altamirano-Castillo' \\ Pedro Sánchez-Tapia' \\ Carlos Martínez-Sánchez' \\ 'Coronary Care Unit, National \\ Institute of Cardiology in Mexico \\ City, Mexico City, Mexico; \\ ${ }^{2}$ Department of Clinical Research, \\ National Institute of Cardiology \\ in Mexico City, Mexico City, Mexico; \\ ${ }^{3}$ Catheterization Laboratory, National \\ Institute of Cardiology in Mexico City, \\ Mexico City, Mexico
}

Correspondence: Héctor GonzálezPacheco

Coronary Care Unit, National Institute of Cardiology in Mexico City, Juan Badiano num I Colonia Sección XVI, CP 14080, Tlalpan, Mexico City, Mexico Tel +525554852219

Email hectorglezp@hotmail.com
Background: Among patients with coronary artery disease (CAD), 80\%-90\% present at least one conventional risk factor. On the other hand, lipid profile modification after a cardiovascular event related to acute coronary syndrome (ACS) has been recognized. The prevalence of conventional risk factors and the lipid profile at the time of admission in patients with ACS and significant $\mathrm{CAD}$ (stenosis $\geq 50 \%$ ) determined through coronary angiography is not well described.

Methods: We studied 3,447 patients with a diagnosis of ACS and significant CAD with stenosis $\geq 50 \%$, as shown on angiography. We recorded the presence of conventional risk factors, including smoking, hypertension, dyslipidemia, and diabetes. In addition, we analyzed the lipid profiles within the first 24 hours of admission. We analyzed the studied population and compared findings according to sex.

Results: Most patients $(81.7 \%)$ were male. ST-elevation myocardial infarction was present in $51.3 \%$ of patients, and non-ST-elevation acute coronary syndrome was present in $48.7 \%$. The most frequent risk factor was smoking, which was present in $68 \%$ of patients, followed by hypertension (57.8\%), dyslipidemia (47.5\%), and diabetes $(37.7 \%)$. In women, the most frequent risk factors were hypertension, diabetes, and dyslipidemia, whereas in men, smoking was the most frequent. We identified at least one risk factor in $95.7 \%$ of all patients, two or three risk factors in $62 \%$, and four risk factors in $8.6 \%$ of patients. The lipid profile analysis revealed that $85.1 \%$ of patients had some type of dyslipidemia, and the most frequent was low levels of high-density lipoprotein cholesterol (68.6\% of cases).

Conclusion: We found at least one conventional risk factor in $95.7 \%$ of patients with ACS and significant CAD. The lipid profile analysis revealed that two thirds of cases had low highdensity lipoprotein cholesterol levels.

Keywords: conventional risk factors, HDL-C, acute coronary syndrome, STEMI, NSTEACS

\section{Introduction}

Conventional cardiovascular risk factors, such as hypertension, diabetes, smoking, and dyslipidemia, increase the risk of developing coronary artery disease (CAD) ${ }^{1,2}$ Primary prevention studies have shown that the early detection and aggressive treatment of risk factors prevent cardiovascular events. ${ }^{3,4}$ The INTERHEART study was designed to assess the relevance of different risk factors on myocardial infarct development worldwide. ${ }^{5}$ The analysis of 14 international clinical studies of patients with acute coronary syndrome (ACS) revealed that $85 \%$ had at least one of the conventional risk factors. ${ }^{6}$ 
The relationship between lipid profile and obstructive disease in coronary arteries is well known. Data from the OPERA registry suggests that in patients with different ACS, the strongest predictor of in-hospital death was untreated dyslipidemia. ${ }^{7}$ It has been recognized that alterations in lipid levels, consisting of reductions in total cholesterol (TC), low-density lipoprotein cholesterol (LDL-C), and high-density lipoprotein cholesterol (HDL-C) and increases in triglycerides (TG), occur after an ACS. ${ }^{8}$ An accurate knowledge of baseline lipid levels may affect the initiation of lipid-lowering therapy and the patient's willingness to adhere to a recommendation for long-term lipid-lowering therapy.

Although strong associations exist between risk factors and the occurrence of CAD, angiographic studies in patients without ACS have shown conflicting results between the correlation of risk factors and the severity of coronary atherosclerosis. ${ }^{9,10}$ Previous reports of the prevalence of the risk factors and lipid profiles in ACS have been done in patients without considering the presence or absence of coronary lesions. The aims of our study were to investigate the prevalence of conventional risk factors and the lipid profiles at the time of admission in a cohort of patients with ACS and significant $\mathrm{CAD}$ (stenosis $\geq 50 \%$ ) determined through coronary angiography.

\section{Methods}

This was a cross-sectional study. Information was gathered from the database of the coronary care unit of the National Institute of Cardiology in Mexico City from October 2005 to June 2012. This information included demographic information, cardiac history (prior myocardial infarction, percutaneous coronary intervention or coronary artery bypass graft surgery), clinical characteristics, laboratory tests, and the results of the coronary angiographies. Patients with a diagnosis of ACS were identified and classified as ST-elevation myocardial infarction (STEMI) or non-ST-elevation acute coronary syndrome (NSTEACS) on the basis of clinical characteristics, electrocardiographic changes, and biochemical markers of cardiac necrosis (isoenzyme of creatinine kinase, creatinine phosphokinase or troponin I) according to the American College of Cardiology. ${ }^{11}$

The presence or absence of a history of conventional risk factors (hypertension, diabetes, dyslipidemia, and previous and/or current smoking) was recorded at the time of admission to the coronary care unit and was based on patient/ family self-report or previous medical records. The serum levels of TC, LDL-C, HDL-C, and TG were determined within the first 24 hours of admission. We defined high serum levels as TC $\geq 200 \mathrm{mg} / \mathrm{dL}, \mathrm{LDL}-\mathrm{C} \geq 130 \mathrm{mg} / \mathrm{dL}$, and $\mathrm{TG} \geq 150 \mathrm{mg} / \mathrm{dL}$; a low serum level of HDL-C was defined as $\leq 40 \mathrm{mg} / \mathrm{dL}$. Coronary angiography was performed in the laboratory of hemodynamics in our institution and interpreted by interventionist cardiologists.

We determined the stenosis percentage of the main epicardial coronary arteries, and the extent of CAD was categorized as one-vessel, two-vessel, or three-vessel disease, according to the number of affected vessels.

Only patients with significant CAD, defined as the presence of $\geq 50 \%$ stenosis of any of the epicardial vessels, were included in the study. Patients with normal coronary angiography or mild disease, defined as $<50 \%$ stenosis in any of the epicardial vessels, were excluded, as were patients in whom ACS was considered to be secondary to coronary embolism, arteritis, spontaneous dissection, muscular bridges, or an anomalous origin of the coronary artery.

The body mass index (BMI) was also recorded. Patients were classified as normal (BMI $\leq 24.9 \mathrm{~kg} / \mathrm{m}^{2}$ ), overweight (BMI $\left.25-29.9 \mathrm{~kg} / \mathrm{m}^{2}\right)$, or obese (BMI $\geq 30 \mathrm{~kg} / \mathrm{m}^{2}$ ). The presence of renal dysfunction was established when the level of serum creatinine was $\geq 2 \mathrm{mg}$ or creatinine depuration was $\leq 30 \mathrm{~mL} /$ minute at the time of admission, as calculated according to the Cockcroft-Gault formula. ${ }^{12}$

\section{Statistical analysis}

Patients were stratified by sex for analysis. Categorical variables were reported by frequency and percentage; groups were compared using the chi-square or Fisher's exact test. Continuous variables were reported as medians and 25 th and 75 th percentiles (interquartile range, IQR) according to their distribution and analyzed with a onesample Kolmogorov-Smirnov test; comparisons were made with the Mann-Whitney $U$-test. The results were reported using two-tailed significance. Significance was set at $P \leq 0.05$. All analyses were performed with SPSS version 13 (SPSS, Inc., Chicago, IL, USA) statistical software.

\section{Results}

During the study period, we identified 5,689 patients with ACS, 4,161 of whom were subjected to coronary angiography. In total, 288 patients were excluded due to normal coronary results and/or nonsignificant lesions, 13 patients were excluded due to nonatherosclerotic ACS etiology 
(seven coronary embolisms, four spontaneous dissections, and two arteritis), and 413 patients were excluded due to the lack of a complete lipid profile at the time of admission (Figure 1). We thus analyzed 3,447 patients with ACS and significant coronary lesions $\geq 50 \%$. Table 1 shows the demographic and clinical characteristics of the patients. In total, $81.7 \%$ were male, and $18.3 \%$ were female. The median age of patients was 59 years (IQR 52-68 years), and women were 8 years older than men ( 66 versus 58 years, $P=0.001$ ). STEMI was diagnosed in 1,767 patients $(51.3 \%)$, and NSTEACS was diagnosed in 1,680 patients (48.7\%). In women, NSTEACS was more frequent in women than in men $(59.7 \%$ versus $46.3 \%$, respectively; $P=0.001$ ), whereas STEMI was more frequent in men than in women $(53.7 \%$ versus $40.3 \%$, respectively; $P=0.001$ ). Most patients were overweight, with a BMI $>25 \mathrm{~kg} / \mathrm{m}^{2}$, and men had a higher frequency than women (76.1\% versus $65.9 \%$, respectively; $P=0.001)$. At the time of admission, $28.3 \%$ of patients had a history of statin treatment. A previous infarct was found in $28.7 \%$ of all patients, with no differences between men and women ( $29.1 \%$ versus $27 \%$, respectively; $P=0.29$ ). Of all patients, $58.9 \%$ had two-vessel or three-vessel disease, with no differences in disease extent between men and women.
In the studied population, the most frequent risk factor was a history of past and/or current smoking (69.1\%), followed by hypertension ( $57.8 \%$ ), dyslipidemia (47.5\%), and diabetes (37.7\%) (Table 2). Excluding smoking, the other conventional risk factors were more frequent in women than in men: hypertension ( $74.9 \%$ versus $54.0 \%$, respectively; $P=0.001$ ), dyslipidemia ( $51.7 \%$ versus $46.5 \%$, respectively; $P=0.02$ ), and diabetes $(51.5 \%$ versus $34.7 \%$, respectively; $P=0.001)$.

In $95.7 \%$ of all patients at least one risk factor was presented, there were not any risk factors in $4.3 \%, 24.9 \%$ had one risk factor, $33.8 \%$ had two, $28.2 \%$ had three, and $8.7 \%$ had all four risk factors. The presence of two or three risk factors was observed in $62 \%$ of the patients, and the incidence was higher in women than in men $(70.2 \%$ vs $60.2 \%, P=0.001)$. In contrast, the presence of all four risk factors was greater in men than in women $(9.3 \%$ vs $6.2 \%$, $P=0.015$ ) (Table 2).

Table 3 shows the prevalence of the risk factors in different ACS groups according to sex. Smoking was the most frequently observed risk factor in both ACS groups (STEMI $71.3 \%$ and NSTEACS 66.8\%). Hypertension (65.6\% versus $50.4 \%, P=0.001)$, dyslipidemia $(53.9 \%$ versus $41.4 \%$, $P=0.001)$, and diabetes $(40.7 \%$ versus $34.9 \%, P=0.001)$ were

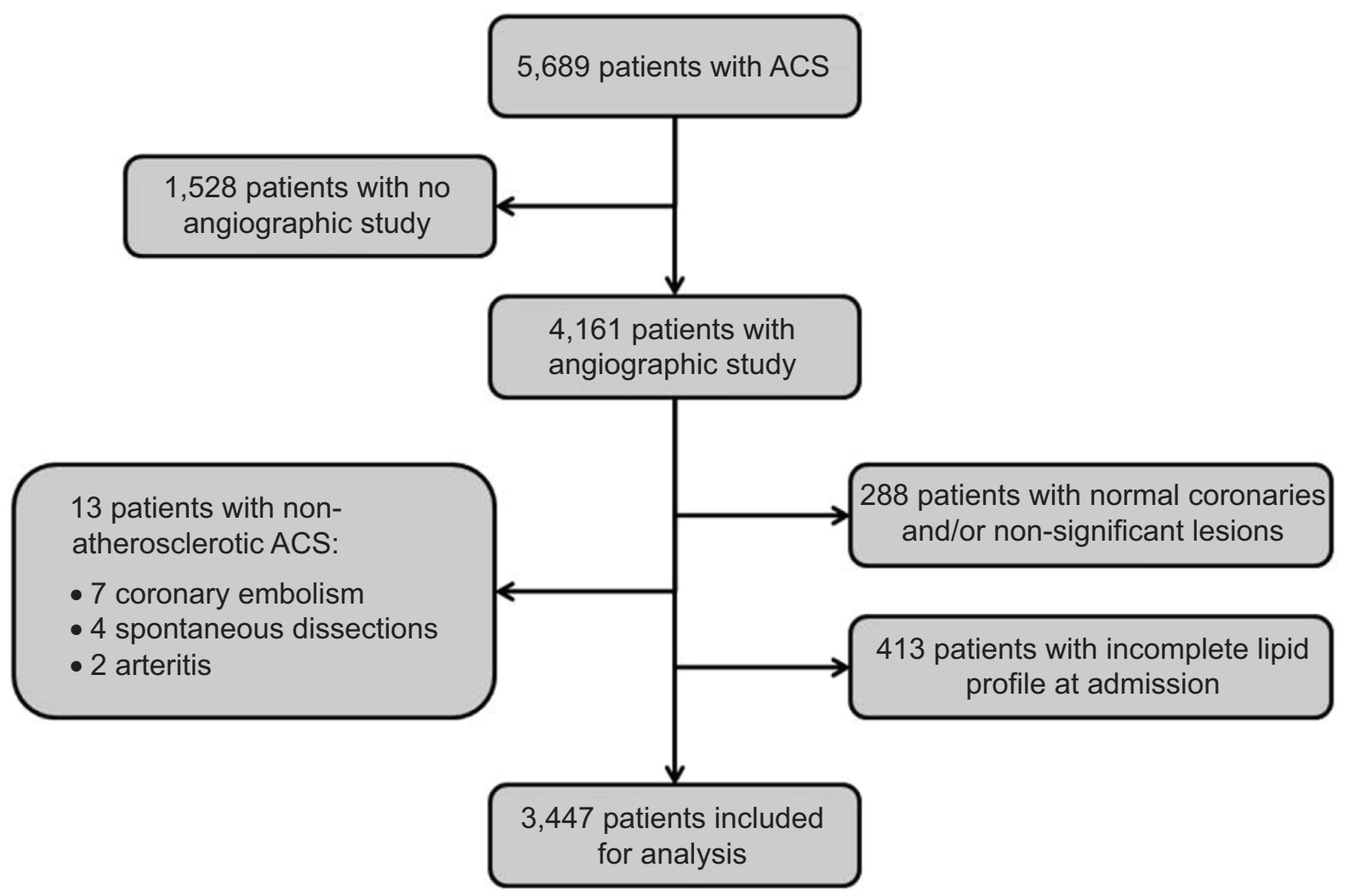

Figure I Patient flow chart.

Abbreviation: ACS, acute coronary syndrome. 
Table I Demographic and clinical characteristics of patients

\begin{tabular}{|c|c|c|c|c|}
\hline & $\begin{array}{l}\text { All patients } \\
(n=3,447)\end{array}$ & $\begin{array}{l}\text { Men } \\
(n=2,822)\end{array}$ & $\begin{array}{l}\text { Women } \\
(n=625)\end{array}$ & $P$-value \\
\hline Median age (IQR) (years) & $59(52-68)$ & $58(51-66)$ & $66(57-73)$ & 0.001 \\
\hline \multicolumn{5}{|l|}{ ACS type } \\
\hline NSTEACS (\%) & 48.7 & 46.3 & 59.7 & 0.001 \\
\hline STEMI (\%) & 51.3 & 53.7 & 40.3 & 0.001 \\
\hline BMI (IQR) $\left(\mathrm{kg} / \mathrm{m}^{2}\right)$ & $27(24.9-29.2)$ & $27(25.1-29.3)$ & $27.1(24.3-29.2)$ & 0.001 \\
\hline $\mathrm{BMI} \leq 24.9 \mathrm{~kg} / \mathrm{m}^{2}(\%)$ & 25.8 & 23.9 & 34.1 & 0.001 \\
\hline BMI $25-29.9 \mathrm{~kg} / \mathrm{m}^{2}(\%)$ & 54.1 & 55.9 & 46.2 & 0.001 \\
\hline $\mathrm{BMI} \geq 30 \mathrm{~kg} / \mathrm{m}^{2}(\%)$ & 20.1 & 20.2 & 19.7 & 0.77 \\
\hline \multicolumn{5}{|l|}{ Medical history } \\
\hline Prior Ml (\%) & 28.7 & 29.1 & 27.0 & 0.29 \\
\hline Prior $\mathrm{PCl}(\%)$ & 14.3 & 15.0 & 10.9 & 0.007 \\
\hline Prior CABG (\%) & 4.2 & 4.3 & 3.8 & 0.61 \\
\hline Renal dysfunction* (\%) & 5.1 & 4.9 & 6.1 & 0.22 \\
\hline Previous statin therapy (\%) & 28.3 & 28.1 & 29.1 & 0.62 \\
\hline Familial history of CAD (\%) & 10.3 & 10.9 & 10.2 & 0.59 \\
\hline \multicolumn{5}{|l|}{ Disease extent } \\
\hline One-vessel disease (\%) & $4 I . I$ & 41.5 & 39.4 & 0.33 \\
\hline Two-vessel disease (\%) & 29.5 & 29.8 & 28.3 & 0.47 \\
\hline Three-vessel disease (\%) & 29.4 & 28.8 & 32.3 & 0.07 \\
\hline
\end{tabular}

Notes: *Creatinine was $\geq 2 \mathrm{mg}$ or creatinine depuration was $\leq 30 \mathrm{~mL} /$ minute at the time of admission.

Abbreviations: ACS, acute coronary syndrome; BMI, body mass index; CABG, coronary artery bypass grafting; CAD, coronary artery disease; IQR, interquartile range; MI, myocardial infarction; NSTEACS, non-ST-elevation acute coronary syndrome; PCl, percutaneous coronary intervention; STEMI, ST-elevation myocardial infarction.

more common in the NSTEACS group than in the STEMI group, respectively. In both ACS groups, the women had a higher prevalence of hypertension and diabetes $(P=0.001)$ and a lower prevalence of smoking history $(P=0.001)$. Of the 1,680 patients with NSTEACS, only $2.6 \%$ had no risk factor compared with $6.8 \%$ of the 1,767 patients with STEMI (Figure 2).

The blood lipid analysis showed that the median levels were $167 \mathrm{mg} / \mathrm{dL}$ (IQR, 138-198 mg/dL) for TC, $98 \mathrm{mg} / \mathrm{dL}$ (IQR, $74-123 \mathrm{mg} / \mathrm{dL}$ ) for LDL-C, $36 \mathrm{mg} / \mathrm{dL}$ (IQR, 31.5-42 mg/dL) for HDL-C, and $150 \mathrm{mg} / \mathrm{dL}$ (IQR, 113-200 mg/dL) for TG (Table 4). TC was higher in women than in men $(170 \mathrm{mg} / \mathrm{dL}$ versus $166 \mathrm{mg} / \mathrm{dL}$, respectively; $P=0.04)$, and HDL-C levels were lower in men than in women $(36 \mathrm{mg} / \mathrm{dL}$ versus $40 \mathrm{mg} / \mathrm{dL}$, respectively; $P=0.001)$. At least one abnormal level in the lipid profile was found in $85.1 \%$ of patients, and this finding was more frequent in men than in women $(86.4 \%$ versus $79.0 \%$, respectively; $P=0.001$ ). The most frequent lipid alteration $(68.6 \%)$ was low levels of HDL-C, followed by high TG levels (50.3\%), high levels of LDL-C (20.3\%), and high levels of TC (24.1\%).

\section{Discussion}

In this study, we only included patients with ACS and $\mathrm{CAD}$ with stenosis $\geq 50 \%$. We found that the prevalence of conventional risk factors was very high: $95.7 \%$ of patients

Table 2 Prevalence of conventional risk factors

\begin{tabular}{|c|c|c|c|c|}
\hline & $\begin{array}{l}\text { All patients } \\
(n=3,447)\end{array}$ & $\begin{array}{l}\text { Men } \\
(n=2,822)\end{array}$ & $\begin{array}{l}\text { Women } \\
(n=625)\end{array}$ & $P$-value \\
\hline Past/current smoking (\%) & 69.1 & 75.7 & 39.5 & 0.001 \\
\hline Hypertension (\%) & 57.8 & 54.0 & 74.9 & 0.001 \\
\hline Dyslipidemia (\%) & 47.5 & 46.5 & 51.7 & 0.02 \\
\hline Diabetes (\%) & 37.7 & 34.7 & 51.5 & 0.0001 \\
\hline \multicolumn{5}{|l|}{ Number of risk factors (\%) } \\
\hline 0 & 4.3 & 4.4 & 3.8 & 0.58 \\
\hline I & 24.9 & 26.1 & 19.7 & 0.001 \\
\hline 2 & 33.8 & 33.0 & 37.8 & 0.022 \\
\hline 3 & 28.2 & 27.3 & 32.5 & 0.009 \\
\hline 4 & 8.7 & 9.3 & 6.2 & 0.015 \\
\hline
\end{tabular}


Table 3 The prevalence of the risk factors in different acute coronary syndrome groups according to sex

\begin{tabular}{|c|c|c|c|c|c|c|c|c|}
\hline & \multicolumn{4}{|l|}{ STEMI } & \multicolumn{4}{|l|}{ NSTEACS } \\
\hline & $\begin{array}{l}\text { All patients } \\
(n=1,767)\end{array}$ & $\begin{array}{l}\text { Men } \\
(n=I, 5 \mid 5)\end{array}$ & $\begin{array}{l}\text { Women } \\
(n=252)\end{array}$ & $P$-value & $\begin{array}{l}\text { All patients } \\
(n=1,680)\end{array}$ & $\begin{array}{l}\text { Men } \\
(n=I, 307)\end{array}$ & $\begin{array}{l}\text { Women } \\
(n=373)\end{array}$ & $P$-value \\
\hline Past/current smoking (\%) & 71.3 & 76.2 & 41.3 & 0.001 & 66.8 & 75.0 & 38.3 & 0.001 \\
\hline Hypertension (\%) & 50.4 & 47.7 & 67.1 & 0.001 & 65.6 & 61.4 & 80.2 & 0.001 \\
\hline Dyslipidemia (\%) & 41.4 & 40.8 & 44.8 & 0.22 & 53.3 & 53.2 & 56.3 & 0.28 \\
\hline Diabetes (\%) & 34.9 & 32.5 & 49.2 & 0.001 & 40.7 & 37.1 & 53.1 & 0.001 \\
\hline
\end{tabular}

Abbreviations: NSTEACS, non-ST-elevation acute coronary syndrome; STEMI, ST-elevation myocardial infarction.

presented at least one of the four risk factors (smoking, hypertension, diabetes, and dyslipidemia). The lipid profile analysis demonstrated the presence of some type of dyslipidemia in $85.1 \%$ of all patients, with low HDL-C levels having the highest prevalence.

This prevalence of conventional risk factors is higher than reported in the overall population with ACS. There is little information on the prevalence of conventional risk factors in patients with ACS and significant lesions in their coronary arteries.

One of the most relevant advances in the knowledge of CAD is the role played by the different risk factors in its development, in which smoking, arterial hypertension, diabetes, and dyslipidemia participate as independent factors; ${ }^{13-16}$ their role in the prognosis of ACS patients has become of great interest. It is possible to establish a relationship between the number of conventional risk factors for $\mathrm{CAD}$ and mortality after the first myocardial infarct. ${ }^{17}$

In the past, it was thought that more than $50 \%$ of patients with CAD had none of the conventional risk factors. ${ }^{18}$ However, Greenland et $\mathrm{al}^{19}$ who analyzed three prospective studies, demonstrated a high prevalence of one or more risk factors for CAD in individuals who developed both fatal and nonfatal CAD events during follow-up. More recently, reports on ACS patients have supported this concept; Khot et $\mathrm{al}^{6}$ analyzed 122,458 patients in 14 clinical studies on ACS and demonstrated that approximately $85 \%$ of patients had at least one of the four conventional risk factors. Roe et $\mathrm{al}^{20}$ in a subanalysis of the CRUSADE (Can Rapid risk stratification of Unstable angina patients Suppress ADverse outcomes with Early implementation of the ACC/AHA guidelines) registry, reported that $10.5 \%$ of patients with myocardial infarction without ST-elevation did not have any of the conventional risk factors. Canto et $\mathrm{al}^{17}$ analyzed five traditional risk factors (hypertension, smoking, dyslipidemia, diabetes, and family history of CAD) and the relation between the number of risk factors and intrahospital mortality in patients with a first myocardial infarct. They found that of 542,000 patients analyzed, $14.4 \%$ did not have identified risk factors, $81 \%$ had one to three risk factors, and $4.5 \%$ had four or five risk factors. However, these studies included all of the ACS patients without analyzing patients with angiographically significant CAD. We found a higher prevalence of conventional risk factors than that reported in ACS patients, as $95.7 \%$ of our patients had at least one risk factor, and there was no sexdependent difference (men, 95.6\%; women, 96.2\%). The presence of all four risk factors was higher in men than in women $(9.3 \%$ versus $6.2 \%$, respectively; $P=0.015)$. The differences in the prevalence of conventional risk factors

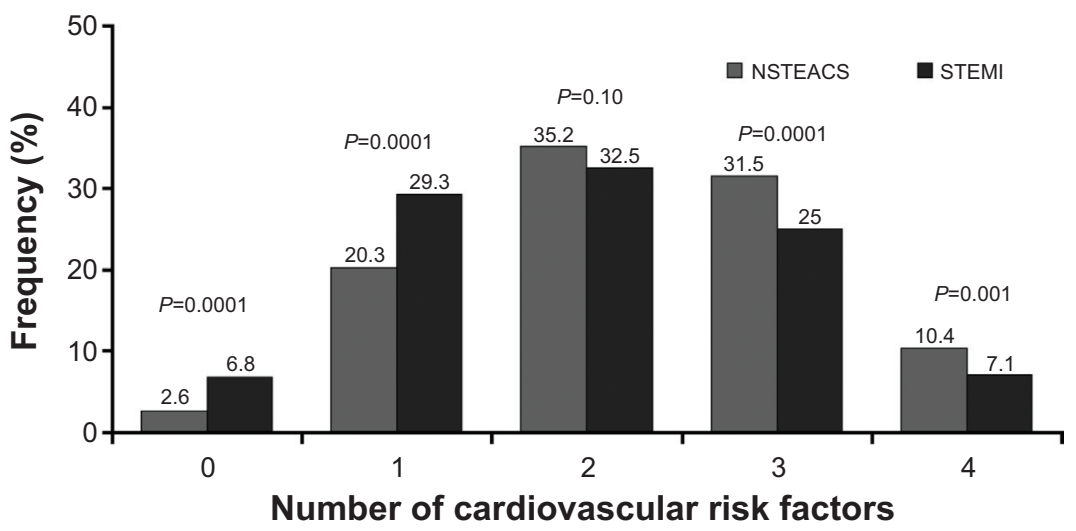

Figure 2 Number of conventional cardiovascular risk factors in the different ACS groups.

Abbreviations: ACS, acute coronary syndrome; NSTEACS, non-ST-elevation acute coronary syndrome; STEMI, ST-elevation myocardial infarction. 
Table 4 Lipid profiles of patients with acute coronary syndrome

\begin{tabular}{|c|c|c|c|c|}
\hline & $\begin{array}{l}\text { All patients } \\
(n=3,447)\end{array}$ & $\begin{array}{l}\text { Men } \\
(n=2,822)\end{array}$ & $\begin{array}{l}\text { Women } \\
(n=625)\end{array}$ & $P$-value \\
\hline Total cholesterol (IQR) (mg/dL) & $167(138-198)$ & $166(138-197)$ & I70 (I39-204) & 0.04 \\
\hline $\mathrm{TC} \geq 200 \mathrm{mg} / \mathrm{dL}(\%)$ & 24.1 & 23.2 & 28 & \\
\hline $\mathrm{TC}<200 \mathrm{mg} / \mathrm{dL}(\%)$ & 75.9 & 76.8 & 72.0 & 0.01 \\
\hline LDL-C (IQR) (mg/dL) & $98(74-123)$ & $98(74-122)$ & $100(72-124)$ & 0.83 \\
\hline LDL-C $\geq 130$ mg/dL (\%) & 20.3 & 20.4 & 20.0 & \\
\hline LDL-C < 130 mg/dL (\%) & 79.7 & 79.6 & 80.0 & 0.80 \\
\hline HDL-C (IQR) (mg/dL) & $36(31.5-42)$ & $36(3|-4|)$ & $40(34-46)$ & 0.001 \\
\hline $\mathrm{HDL}-\mathrm{C} \geq 40 \mathrm{mg} / \mathrm{dL}(\%)$ & 31.4 & 28.0 & 46.9 & \\
\hline $\mathrm{HDL}-\mathrm{C}<40 \mathrm{mg} / \mathrm{dL}(\%)$ & 68.6 & 72.0 & 53.1 & 0.001 \\
\hline Triglyceride (IQR) (mg/dL) & $150(\mid 13-200)$ & $150(|| \mid 2-200)$ & I5I (II5-200) & 0.64 \\
\hline $\mathrm{TG} \geq 150 \mathrm{mg} / \mathrm{dL}(\%)$ & 50.3 & 50.1 & 51.2 & \\
\hline $\mathrm{TG}<150 \mathrm{mg} / \mathrm{dL}(\%)$ & 49.7 & 49.9 & 48.8 & 0.63 \\
\hline Dyslipidemia* (\%) & 85.1 & 86.4 & 79.0 & 0.001 \\
\hline
\end{tabular}

Note: *Determined by the presence of any abnormal lipid level.

Abbreviations: HDL-C, high-density lipoprotein cholesterol; IQR, interquartile range; LDL-C, low-density lipoprotein cholesterol; TC, total cholesterol; TG, triglyceride.

in our study compared with reports in the literature arise because our population included patients with significant CAD demonstrated angiographically, and this population has not been reported previously. Saab et $\mathrm{al}^{21}$ studied 941 patients with a first ACS, and $98 \%$ of them presented at least one risk factor. However, that study also considered age $>65$ years, renal failure, and a family history of CAD as risk factors, none of which were included in our analysis.

Women in ACS registries tend to be older than men and are more prone to hypertension and diabetes. In contrast, smoking and dyslipidemia are higher in men..$^{22,23}$ These data are similar to those found in our study, in which women were older and more frequently had a history of hypertension, diabetes, and dyslipidemia. Smoking was more frequent in men.

In our series, the risk factors with the highest prevalence were past and/or current smoking and hypertension, at $69.1 \%$ and $57.7 \%$, respectively. A similar finding was reported in the INTERHEART study with regard to smoking. That study included 29,000 individuals from 52 countries. ${ }^{5}$ The study demonstrated that the two risk predictors for an acute myocardial infarct were smoking and an abnormal relation between apolipoprotein B/apolipoprotein A-1. No differences were found due to ethnicity, geographic region, or sex.

Women have been considered to have less atherosclerotic coronary obstructive disease than men, as reported by Dey et $\mathrm{al}^{24}$ who analyzed GRACE (Global Registry of Acute Coronary Events) registry data from 19,117 men and 7,638 women with ACS in whom coronary angiography had been performed. Men were more prone to have advanced coronary disease with $\geq 50 \%$ lesions ( $94 \%$ of men and $88 \%$ of women). The distribution pattern of the risk factors was similar to our results: hypertension and diabetes were higher in women, and smoking was higher in men. Shaw et $\mathrm{a}^{25}$ analyzed American College of Cardiology-National Cardiovascular Data Registry data from 826,215 patients with stable angina or ACS and coronary lesions, and they found no differences in the prevalence of risk factors in the various ethnic groups studied (in order of prevalence): hypertension, dyslipidemia, diabetes, and smoking. However, in contrast to our study, only current smoking was investigated and not only in patients with ACS. Neither the distribution of conventional risk factors nor their prevalence in the different acute coronary syndromes have been reported until now. Reports by Roe et $\mathrm{al}^{20}$ included patients with myocardial infarction without ST-elevation, and Canto et $\mathrm{al}^{17}$ studied patients with myocardial infarct without specifying the type.

Our analyses revealed that smoking was the most prevalent risk factor in the two types of ACS (71.3\% STEMI and $66.8 \%$ NSTEACS). It is noteworthy that the NSTEACS group of patients was more likely to have a history of hypertension, dyslipidemia, and diabetes, and therefore to have a higher number of conventional risk factors. This finding is consistent with previous studies among patients with ACS; STEMI is associated with smoking, whereas hypertension, diabetes, and hyperlipidemia are related to NSTEACS. ${ }^{26}$ Interestingly, the identification of each risk factor at presentation does not improve the prediction of short-term mortality after myocardial infarction. ${ }^{27}$ However, our findings on the difference in the number of risk factors in the two ACS classifications could be important. In previous observations, data from the CRUSADE registry have shown that STEMI patients without 
documented traditional risk factors had a worse in-hospital prognosis, and a National Registry of Myocardial Infarction study demonstrated that among patients with incident acute myocardial infarction without prior cardiovascular disease, in-hospital mortality was inversely related to the number of coronary heart disease risk factors. ${ }^{17,20}$

The presence of risk factors favors the development of recurrent cardiovascular events. When epidemiological studies began, some prior evidence suggested a relationship between total cholesterol and cardiovascular disease. ${ }^{28}$ The results of an observational study show that in patients with ST-segment elevation myocardial infarction and STEMI, among the strongest predictors of in-hospital death was untreated dyslipidemia. ${ }^{7}$ Clinically significant alterations in lipids occur after an ACS. ${ }^{8}$ From the time of admission until the next morning, the TC and LDL-C levels can undergo a change of $7 \%$ and $10 \%$, respectively, in patients with myocardial infarct and 5\% and 6\% in those with unstable angina. ${ }^{29}$ Therefore, current guidelines recommend measurement of serum lipids after admission for patients with an ACS event. ${ }^{30}$ This is of importance because in-hospital lipid testing was strongly associated with the initiation of statin therapy at discharge in patients with an ACS cardiovascular event. $^{31}$

Pitt et $\mathrm{al}^{32}$ suggest that mean lipid levels vary relatively little in the 4 days after an ACS event and can be used to guide selection of lipid-lowering medication. Accurate knowledge of baseline lipid levels in patients admitted with ACS might allow for an early classification of eventual dyslipidemia and thereby enable the selection of the type and intensity of lipidlowering therapy. The lipid profile in our patients revealed that a high percentage $(85.1 \%)$ had at least one alteration in lipid levels, revealing different values from those reported by the patients with a history of dyslipidemia at the time of admission. On one hand, this result could reflect that attention is primarily focused on determining only TC and LDL-C levels, which are the main targets recommended in international guidelines for the prevention of cardiovascular disease. ${ }^{33}$ On the other hand, this result could be due to an underestimation of the true prevalence of dyslipidemia as a risk factor. LDL-C and HDL-C have been considered to exert opposite effects on the risk of myocardial infarction. ${ }^{34}$ Studies have shown that, in addition to elevated LDL-C levels, low HDL-C levels are an independent risk predictor for $\mathrm{CAD}$, with a strong inverse association between HDL-C levels and ACS rates. ${ }^{35}$ Our study population showed that the main alteration in lipid levels was low HDL-C levels in a high percentage of patients $(68.6 \%)$; interestingly the percentage of patients with low levels of LDL-C was $80 \%$. Our findings are consistent with previous studies. In one of those studies of patients hospitalized with some type of CAD, approximately half had LDL-C levels $<100 \mathrm{mg} / \mathrm{dL}$ at admission, and more than half had HDL-C levels $<40 \mathrm{mg} / \mathrm{dL}$ at admission. ${ }^{36}$ Another study performed only in ACS patients revealed that $56.6 \%$ had low HDL-C levels. ${ }^{37}$ These findings have clinical relevance for the observations shown by previous studies in patients with stable ischemic heart disease, in which a low HDL-C was associated with increased risk for death and nonfatal myocardial infarction, even among statin-treated patients who achieve LDL-C $<70 \mathrm{mg} / \mathrm{dL} .^{38,39}$

Although epidemiological studies have shown a reduction in TC and LDL-C levels in the general population, levels of HDL-C have diminished significantly; this reduction in HDL-C levels has been attributed to the increase in the frequency of obesity, insulin resistance, and diabetes. ${ }^{36,40}$ A better knowledge of the lipid profile in patients with ACS allows for identifying some types of dyslipidemia and for tailoring specific treatment.

Our study has the limitations of a retrospective observational analysis of a group of ACS patients. Risk-factor identification was based on the information provided by patients or their relatives. Identifying risk factors in this manner leads to an underestimation of their true prevalence; however, this is the method used in recent studies. ${ }^{6,17}$ Further, our data came from only one hospital; therefore, the results cannot be generalized to other geographical regions. We did not investigate the potential relationship between the prevalence of risk factors and the type of ACS according to sex.

The lipid profile was determined in one blood sample taken within the first 24 hours after admission; there is controversy regarding lipid levels analyzed during the first hours after admission for ACS. We cannot confirm whether the lipid analysis was affected by the ACS event. However, US guidelines recommend that the lipid profile be determined within the first 24 hours of admission in ACS patients. ${ }^{30}$

We did not obtain any information on the use of other lipidemia-decreasing agents, aside from statins, which could influence the blood lipid profile. We did not analyze the relationship between the different risk factors or the different lipid levels and the extent of the disease.

\section{Conclusion}

In ACS patients with significant CAD demonstrated angiographically, the prevalence of conventional risk factors was very high, and $96 \%$ of patients had at least one risk factor. This prevalence is higher than that reported in all ACS 
patients. Smoking and hypertension were the most frequent risk factors.

Hypertension, diabetes, and dyslipidemia predominated in women and therefore caused higher comorbidity, which could have prognostic implications. Most patients presented with one to three risk factors. The lipid profile analysis demonstrated the presence of some type of dyslipidemia in $85.1 \%$ of all patients, with low HDL-C levels having the highest prevalence of all alterations. Determining the lipid profile of patients admitted with ACS might allow for an early classification of eventual dyslipidemia and thereby enable the selection of the type and intensity of lipid-lowering therapy. Many of these risk factors, including blood lipids, are modifiable and amenable to treatment.

\section{Acknowledgments}

The authors thank the secretarial staff of the Coronary Care Unit, Leticia Casiano and Benita Medrano, for their valuable cooperation in the preparation of this manuscript.

\section{Disclosure}

There was no funding for this research. The authors report no conflicts of interest in this work.

\section{References}

1. Grundy SM, Pasternak R, Greenland P, Smith S, Fuster V. Assessment of cardiovascular risk by use of multiple-risk-factor assessment equations: a statement for healthcare professionals from the American Heart Association and the American College of Cardiology. Circulation. 1999; 100(13):1481-1492.

2. Pasternak RC, Grundy SM, Levy D, Thompson PD. 27th Bethesda Conference: matching the intensity of risk factor management with the hazard for coronary disease events. Task Force 3. Spectrum of risk factors for coronary heart disease. J Am Coll Cardiol. 1996;27(5):978-990.

3. Heart Protection Study Collaborative Group. MRC/BHF Heart Protection Study of cholesterol lowering with simvastatin in 20,536 highrisk individuals: a randomised placebo-controlled trial. Lancet. 2002; 360(9326):7-22.

4. Sever PS, Dahlöf B, Poulter NR, et al; ASCOT investigators. Prevention of coronary and stroke events with atorvastatin in hypertensive patients who have average or lower-than-average cholesterol concentrations, in the Anglo-Scandinavian Cardiac Outcomes Trial - Lipid Lowering Arm (ASCOT-LLA): a multicentre randomized controlled trial. Lancet. 2003; 361(9364):1149-1158.

5. Yusuf S, Hawken S, Ounpuu S, et al; INTERHEART Study Investigators. Effect of potentially modifiable risk factors associated with myocardial infarction in 52 countries (the INTERHEART study): case-control study. Lancet. 2004;364(9438):937-952.

6. Khot UN, Khot MB, Bajzer CT, et al. Prevalence of conventional risk factors in patients with coronary heart disease. JAMA. 2003;290(7): 898-904.

7. Montalescot G, Dallongeville J, Van Belle E, et al; OPERA Investigators. STEMI and NSTEMI: are they so different? 1 year outcomes in acute myocardial infarction as defined by the ESC/ACC definition (the OPERA registry). Eur Heart J. 2007;28(12):1409-1417.

8. Rosenson RS. Myocardial injury: the acute phase response and lipoprotein metabolism. J Am Coll Cardiol. 1993;22(3):933-940.
9. Hasin Y, Eisenberg S, Friedlander J, Lewis BS, Gotsman MS. Relationship between extent of coronary artery disease and correlative risk factors. Am Heart J. 1979;98(5):555-561.

10. Krishnaswami S, Jose VJ, Joseph G. Lack of correlation between coronary risk factors and CAD severity. Int J Cardiol. 1994;47(1):37-43.

11. Cannon CP, Battler A, Brindis RG, et al. American College of Cardiology key data elements and definitions for measuring the clinical management and outcomes of patients with acute coronary syndromes. A report of the American College of Cardiology Task Force on Clinical Data Standards (Acute Coronary Syndromes Writing Committee). J Am Coll Cardiol. 2001;38(7):2114-2130.

12. Cockcroft DW, Gault MH. Prediction of creatinine clearance from serum creatinine. Nephron. 1976;16(1):31-41.

13. MacMahon S, Peto R, Cutler J, et al. Blood pressure, stroke, and coronary heart disease. Part 1, Prolonged differences in blood pressure: prospective observational studies corrected for the regression dilution bias. Lancet. 1990;335(8692):765-774.

14. Stamler J, Vaccaro O, Neaton JD, Wentworth D. Diabetes, other risk factors, and 12-yr cardiovascular mortality for men screened in the Multiple Risk Factor Intervention Trial. Diabetes Care. 1993;16(2):434-444.

15. Verschuren WM, Jacobs DR, Bloemberg BP, et al. Serum total cholesterol and long-term coronary heart disease mortality in different cultures. Twenty-five-year follow-up of the seven countries study. JAMA. 1995;274(2):131-136.

16. Houterman S, Verschuren WM, Kromhout D. Smoking, blood pressure and serum cholesterol-effects on 20-year mortality. Epidemiology. 2003; 14(1):24-29.

17. Canto JG, Kiefe CI, Rogers WJ, et al; NRMI Investigators. Number of coronary heart disease risk factors and mortality in patients with first myocardial infarction. JAMA. 2011;306(19):2120-2127.

18. Futterman LG, Lemberg L. Fifty percent of patients with coronary artery disease do not have any of the conventional risk factors. Am J Crit Care. 1998;7(3):240-244.

19. Greenland P, Knoll MD, Stamler J, et al. Major risk factors as antecedents of fatal and nonfatal coronary heart disease events. JAMA. 2003; 290(7):891-897.

20. Roe MT, Halabi AR, Metha RH, et al. Documented traditional cardiovascular risk factors and mortality in non-ST-segment elevation myocardial infarction. Am Heart J. 2007;153(4):507-514.

21. Saab F, Mukherjee D, Gurm H, et al. Risk Factors in first presentation acute coronary syndromes (ACS): how do we move from population to individualized risk prediction? Angiology. 2009;60(6):663-667.

22. Hasdai D, Porter A, Rosengren A, Behar S, Boyko V, Battler A. Effect of gender on outcomes of acute coronary syndromes. Am J Cardiol. 2003;91(12):1466-1469, A6.

23. Radovanovic D, Erne P, Urban P, Bertel O, Rickli H, Gaspoz JM; AMIS Plus Investigators. Gender differences in management and outcomes in patients with acute coronary syndromes: results on 20,290 patients from the AMIS Plus Registry. Heart. 2007;93(11):1369-1375.

24. Dey S, Flather MD, Devlin G, et al; Global Registry of Acute Coronary Events investigators. Sex-related differences in the presentation, treatment and outcomes among patients with acute coronary syndromes: the Global Registry of Acute Coronary Events. Heart. 2009; 95(1):20-26.

25. Shaw LJ, Shaw RE, Merz CN, et al; American College of CardiologyNational Cardiovascular Data Registry Investigators. Impact of ethnicity and gender differences on angiographic coronary artery disease prevalence and in-hospital mortality in the American College of Cardiology-National Cardiovascular Data Registry. Circulation. 2008; 117(14):1787-1801.

26. Rosengren A, Wallentin L, Simoons M, et al. Cardiovascular risk factors and clinical presentation in acute coronary syndromes. Heart. 2005; 91(9):1141-1147.

27. Canto JG, Kiefe CI, Rogers WJ, et al; NRMI Investigators. Atherosclerotic risk factors and their association with hospital mortality among patients with first myocardial infarction (from the National Registry of Myocardial Infarction). Am J Cardiol. 2012;110(9):1256-1261. 
28. Anderson KM, Castelli WP, Levy D. Cholesterol and mortality. 30 years of follow-up from the Framingham study. JAMA. 1987;257(16): 2176-2180.

29. Fresco C, Maggioni AP, Signorini S, et al; LATIN Investigators. Variations in lipoprotein levels after myocardial infarction and unstable angina: the LATIN trial. Ital Heart J. 2002;3(10):587-592.

30. Canadian Cardiovascular Society; American Academy of Family Physicians; American College of Cardiology; American Heart Association; Antman EM, Hand M, Armstrong PW, et al. 2007 focused update of the ACC/AHA 2004 guidelines for the management of patients with ST-elevation myocardial infarction. A report of the American College of Cardiology/American Heart Association Task Force on Practice Guidelines. J Am Coll Cardiol. 2008;51(2):210-247.

31. Ko DT, Alter DA, Newman AM, Donovan LR, Tu JV. Association between lipid testing and statin therapy in acute myocardial infarction patients. Am Heart J. 2005;150(3):419-425.

32. Pitt B, Loscalzo J, Ycas J, Raichlen JS. Lipid levels after acute coronary syndromes. J Am Coll Cardiol. 2008;51(15):1440-1445.

33. European Association for Cardiovascular Prevention and Rehabilitation; Reiner Z, Catapano AL, De Backer G, et al; ESC Committee for Practice Guidelines (CPG) 2008-2010 and 2010-2012 Committees. ESC/EAS Guidelines for the management of dyslipidaemias: the Task Force for the management of dyslipidaemias of the European Society of Cardiology (ESC) and the European Atherosclerosis Society (EAS). Eur Heart J. 2011;32(14):1769-1818.
34. Di Angelantonio E, Sarwar N, Perry P, et al; Emerging Risk Factors Collaboration. Major lipids, apolipoproteins, and risk of vascular disease. JAMA. 2009;302(18):1993-2000.

35. Assmann G, Schulte H, von Eckardstein A, Huang Y. High-density lipoprotein cholesterol as a predictor of coronary heart disease risk. The PROCAM experience and pathophysiological implications for reverse cholesterol transport. Atherosclerosis. 1996;124 Suppl:S11-S20.

36. Sachdeva A, Cannon CP, Deedwania PC, et al. Lipid levels in patients hospitalized with coronary artery disease: an analysis of 136,905 hospitalizations in Get With The Guidelines. Am Heart J. 2009;157(1): 111-117.e2.

37. Pintó X, Millán J, Muñoz A, et al. A very high prevalence of low HDL cholesterol in Spanish patients with acute coronary syndromes. Clin Cardiol. 2010;33(7):418-423.

38. Barter P, Gotto AM, LaRosa JC, et al; Treating to New Targets Investigators. HDL cholesterol, very low levels of LDL cholesterol, and cardiovascular events. $N$ Engl J Med. 2007;357(13):1301-1310.

39. Acharjee S, Boden WE, Hartigan PM, et al. Low levels of high-density lipoprotein cholesterol and increased risk of cardiovascular events in stable ischemic heart disease patients: A post-hoc analysis from the COURAGE Trial (Clinical Outcomes Utilizing Revascularization and Aggressive Drug Evaluation). J Am Coll Cardiol. 2013;62(20):1826-1833.

40. Gregg EW, Cheng YJ, Cadwell BL, et al. Secular trends in cardiovascular disease risk factors according to body mass index in US adults. JAMA. 2005;293(15):1868-1874.
Therapeutics and Clinical Risk Management

\section{Publish your work in this journal}

Therapeutics and Clinical Risk Management is an international, peerreviewed journal of clinical therapeutics and risk management, focusing on concise rapid reporting of clinical studies in all therapeutic areas, outcomes, safety, and programs for the effective, safe, and sustained use of medicines. This journal is indexed on PubMed Central, CAS,

\section{Dovepress}

EMBase, Scopus and the Elsevier Bibliographic databases. The manuscript management system is completely online and includes a very quick and fair peer-review system, which is all easy to use. Visit http://www.dovepress.com/testimonials.php to read real quotes from published authors.

Submit your manuscript here: http://www.dovepress.com/therapeutics-and-clinical-risk-management-journal 